\title{
Comparison of Depression and Quality of Life after Coronary Artery Bypass Graft Surgery in Patients With and Without Type D Personalities
}

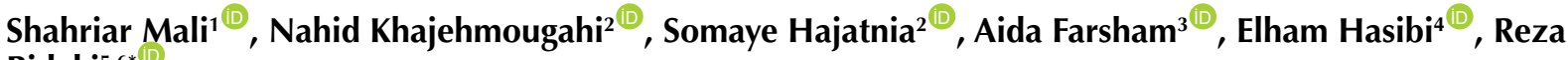 \\ Bidaki $^{5,6^{*}}$ \\ 'Yazd Cardiovascular Resesrch Center, Shahid Sadoughi University of Medical Sciences, Yazd, Iran \\ ${ }^{2}$ Ahvaz Jundishapur University of Medical Sciences, Ahvaz, Iran \\ ${ }^{3}$ Department of Clinical Psychology, Alzahra University, Tehran, Iran \\ ${ }^{4}$ Department of Cardiology, Hormozgan University of Medical Sciences, Bandar Abbas, Iran \\ ${ }^{5}$ Research Center of Addiction and Behavioral Sciences, Shahid Sadoughi University of Medical Sciences, Yazd, Iran \\ ${ }^{6}$ Diabetes Research Center, Shahid Sadoughi University of Medical Sciences, Yazd, Iran
}

*Corresponding Author: Reza Bidaki, M.D., Professor of Psychiatry, Research Center of Addiction and Behavioral Sciences, Shahid Sadoughi University of Medical Sciences, Yazd, Iran. Tel: +98-3532632006, Email: Reza_bidaki@ yahoo.com

Received November 29, 2020; Accepted June 19, 2021; Online Published August 1, 2021

\begin{abstract}
Background: Recently, some studies have investigated type D personality as a critical factor in developing depression and reducing the quality of life.

Objectives: This study aimed to compare depression and quality of life after coronary artery bypass graft surgery in patients with and without type D personalities.

Methods: Sixty-nine participants who underwent coronary artery bypass grafting at Imam Khomeini hospital, Ahvaz, Iran, referred to the cardiac surgery clinic for their first visit (1 to 1.5 months after surgery) were included in the study. All participants completed the World Health Organization Quality of Life questionnaire, type D personality scale, and Beck's Depression Inventory. Finally, depression and quality of life were compared in two groups with and without type D personalities using ANOVA and correlation tests.

Results: The two groups were significantly different in depression and quality of life scores after coronary artery bypass graft surgery. Depression and quality of life impairment were higher in participants with type D personality. There was no significant relationship between depression and quality of life with age, gender, and occupation in participants with type D personality.

Conclusion: Depression and quality of life were higher in patients with type D personality after coronary artery bypass graft surgery than patients without type $\mathrm{D}$ personality. Episodic screening of these patients can prevent future somatic and psychological problems. Keywords: Depression, Quality of Life, Type D Personality, Coronary Artery Bypass
\end{abstract}

\section{Background}

The cardiovascular diseases mortality rate increased by 41\% between 1990-2013. This increase is associated with population growth and aging. ${ }^{1}$ Recently cardiovascular surgery has become more frequent to improve patients' survival and quality of life, even in elderly patients. ${ }^{2}$ The increasing demand and tendency towards surgery make it essential to pay specific attention to these patients and determine their quality of life after surgery. ${ }^{3}$ Different definitions exist regarding health-related quality of life. Quality of life is associated with physical, psychological, and social aspects of an individual affected by their activities, beliefs, expectations, and impressions. ${ }^{4}$

Depression, as a consequence of any surgery, is also widely reported in patients undergoing coronary artery bypass grafting (CABG). ${ }^{5}$ A systematic review showed that depressive symptoms are seen in many patients undergoing CABG before and after the surgery. There is an overall improvement in depressive symptoms post CABG. But it may relapse of depression post CABG for the majority of them. The depression severity pre-operation may involve postoperative resolve. ${ }^{6}$

Depression and it's severity affects the prognosis of heart disease and mortality. ${ }^{7}$ Between $30 \%-40 \%$ of patients undergoing $\mathrm{CABG}$ experience anxiety and depression after surgery. ${ }^{8}$ These patients usually have more risk factors for depression than the general population. ${ }^{9}$ They are less likely to participate in rehabilitation programs, cessation of smoking, follow nutritional and medical regimens, and socially become isolated. ${ }^{8,10}$

Copyright $\odot 2021$ The Author(s). This is an open-access article distributed under the terms of the Creative Commons Attribution License (http:// creativecommons.org/licenses/by/4.0), which permits unrestricted use, distribution, and reproduction in any medium, provided the original work is properly cited. 
Biochemical disturbances related to mood disorders have different mechanisms to affect the prognosis of cardiovascular diseases. Neuropsychological function, ${ }^{11}$ chemical and inflammatory responses, ${ }^{12}$ and even familiar genetic sources for both depression and cardiovascular diseases are under investigation. ${ }^{13}$

Personality has different effects on general health, especially the cardiovascular system. ${ }^{14}$ Patients with personality type $\mathrm{D}$ have more problems with their health in different ways ${ }^{15}$ and worse than patients with other personality types. ${ }^{16}$ Although it is suspected that coronary artery bypass surgery would improve the symptoms related to ischemic heart disease, some patients have such symptoms six months after surgery. It is approved that most of them have type D personality. ${ }^{17}$

Denollet assumed that type $\mathrm{D}$ personality is critical in determining individual differences regarding stress response, complications, psychological events, and mortality risk following cardiovascular diseases. ${ }^{18}$ Individuals with type $\mathrm{D}$ personalities are clinically susceptible to worry, dysphoria, tension, and a pessimistic view of life. They easily get nervous and, in general, less frequently experience positive feelings. While these people readily get negative feelings, they avoid talking about their emotions in interacting with others because of the fear of rejection or devaluation. ${ }^{16,19}$

Type D personality can be associated with many psychological and social problems, including depression, anxiety, ${ }^{20,21}$ post-traumatic stress disorder, low psychological welfare and quality of life, anger, chronic tension, pessimism, and low self-confidence. Evidence shows that type D personality is an essential factor in cardiovascular disease outcomes. ${ }^{16}$ The prevalence of this personality type is estimated at $19 \%$ in the general population and $27 \%$ in cardiovascular patients. ${ }^{22}$

A study on 100 patients under cardiac surgery showed that anxiety and depression improve over time. ${ }^{23}$ Other studies approved those results and suggested that an unhealthy lifestyle may be the cause, but others found an association between type $\mathrm{D}$ personality and cardiac mortality due to aggravated inflammatory responses. ${ }^{12,20,24}$ An Asian study on patients with coronary artery disease showed that type $\mathrm{D}$ personality is an independent predictor of cardiovascular outcome..$^{25}$

\section{Objectives}

As per our knowledge and previous studies, type D personality and depression are two different disorders. Depression is described as a temporary condition, while type $\mathrm{D}$ personality is a more permanent, and symptoms of depression independently predict a poorer disease/health status. On the other hand, this personality type can increase symptoms of depression in cardiac patients, and depression is more common after coronary artery bypass graft, which affects the quality of life. This study evaluated depression and quality of life after coronary artery bypass graft surgery in patients with and without type $\mathrm{D}$ personalities.

\section{Methods}

In this cross-sectional study, 69 participants who underwent coronary artery bypass grafting at Imam Khomeini hospital, Ahvaz, Iran, referred to the Cardiac Surgery Clinic for their first visit (1 to 1.5 months after surgery) were included in the study. Our exclusion criteria were low cardiac output, long time intensive care unit (ICU) admission (more than five days), history of antidepressant and anti-psychotic medical treatment, and poor cooperation.

After giving the necessary explanations about the aim of the study, the privacy of the acquired data, and voluntarism of the participation in the research, all participants completed the WHOQOL-BREF questionnaire (Short form of World Health Organization Quality of Life questionnaire), type $\mathrm{D}$ personality scale, and Beck's Depression Inventory. If participants could not read the questionnaire, the researcher would read the questions out for them. In addition, incomplete questionnaires were excluded from the study.

\subsection{Type D Personality Scale}

Denollet designed the type D personality scale in $1998 .{ }^{18}$ This scale measured negative affectivity and social inhibition together for labeling a person as type D personality. This scale was revised in 2005 and named DS14. ${ }^{19}$ The basis of this scale was the same as the previous version (DS16). Still, it had more items to measure the severity of negative affectivity and social inhibition separately and identify type $\mathrm{D}$ personality as the high level of negative affectivity and social inhibition. Emons et al approved the reliability of SD14 approved the reliability of SD14 in 2007. ${ }^{25}$

\subsection{WHOQOL-BREF Questionnaire}

WHOQOL developed a questionnaire in 2004 to assess the quality of life. ${ }^{26}$ This questionnaire consists of four different domains, including physical, psychological, social relationships, and environmental health, with a total number of 24 questions $(7,6,3$, and 8 questions respectively in each domain). The first two questions do not belong to any domains and evaluate general health and quality of life. Thus, in general, this questionnaire has 26 questions. By carrying out the required calculations, there will be a score of 4 to 20 for each domain, with four accounting for the worst and 20 accounting for the best status in that specific domain. Psychometric characteristics of the adapted Iranian scale have shown that this instrument can also be used in Iran; the intra-cluster correlation coefficient in the retest of the four domains performed at a two-week interval was $75 \%$ to $84 \%$. On the other hand, the Cronbach's alpha and validity coefficients of the scale had proved to be acceptable for Iranian populations. ${ }^{27}$

\subsection{Beck Depression Inventory}

This questionnaire is one of the best psychometric tests for measuring the severity of depression which Aaron $T$ Beck first published in $1961{ }^{28}$ It is a 21 -question multiple- 
Depression and Quality of Life

choice self-report inventory that each question can have four possible responses scored 0 to 3 with a total score of 63. A score of 0-9 indicates minimal depression, and a score of 10-18, 19-29, and 30-63 indicate mild, moderate, and severe depression, respectively. Several studies have evaluated the validity of this inventory. The mean correlation of Beck's Depression Inventory with the Hamilton Depression Rating Scale has been 0.52 - 0.75. 29,30 However, this correlation is more in patients with severe diseases. The correlation between Hamilton Depression Rating Scale and Zung Self-Rating Depression Scale has been 0.4 , which shows the Zung scale is not suitable for quantifying depression. ${ }^{30}$ In addition, several studies have been conducted in Iran that reported this inventory's reliability coefficient from 0.70 to $0.90 .^{31-34}$

\subsection{Statistical Analysis}

Statistical analysis of data was performed using SPSS software, version 22 (Statistical Package for the Social Sciences, version 22.0, SPSS Inc, Chicago, Illinois, USA). Variance analysis and correlation coefficient were used to analyze the acquired data. Chi-square test and Student's $t$ test were used to compare variables between groups. The significance level was considered at 0.05 .

\section{Results}

Among the 69 participants, 50 (72.46\%) were men and 19 (27.45\%) women. Forty-nine participants (71.01\%) had the type D personality, and $20(28.98 \%)$ were in the non-type $\mathrm{D}$ group. There were no significant differences in age and gender between the two groups (Table 1). The prevalence of depression in study participants after CABG was $33 \%$ (23 out of $69 ; 20 \%$ mild, $10 \%$ moderate, and $3 \%$ severe depression), which 21 of whom had type $\mathrm{D}$ personality and only two were in the non-type $\mathrm{D}$ group $(P=0.01)$ (Figure 1).

Overall, the depression score was significantly higher in the type $\mathrm{D}$ personality group than the non-type $\mathrm{D}$ personalities $(P<0.001)$. In other words, participants with type $\mathrm{D}$ personality who underwent $\mathrm{CABG}$ were more susceptible to depression than the non-type D personality. Regarding the quality of life, the type D personality group had significantly lower physical, psychological, social, and environmental dimensions than the non-type $\mathrm{D}$ personality group (Table 2). Quality of life score is set 4 to 20 in each domain; thus, the results showed that

Table 1. Comparison of Gender and Age in Two Study Groups

\begin{tabular}{|c|c|c|c|}
\hline \multirow[b]{2}{*}{ Variables } & \multicolumn{2}{|c|}{ Groups } & \multirow[b]{2}{*}{$P$ value } \\
\hline & $\begin{array}{l}\text { Type D Personality } \\
\text { Group }(n=49)\end{array}$ & $\begin{array}{l}\text { Non-type D Personality } \\
\text { Group }(n=20)\end{array}$ & \\
\hline Age, Mean $\pm S D$ & $56.37 \pm 8.592$ & $55.80 \pm 12.672$ & $0.830^{\mathrm{a}}$ \\
\hline Gender, No. (\%) & & & $0.770^{\mathrm{b}}$ \\
\hline Male & $36(73.5)$ & $14(70.0)$ & \\
\hline Female & $13(26.5)$ & $6(30.0)$ & \\
\hline
\end{tabular}

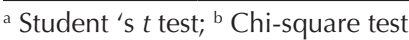

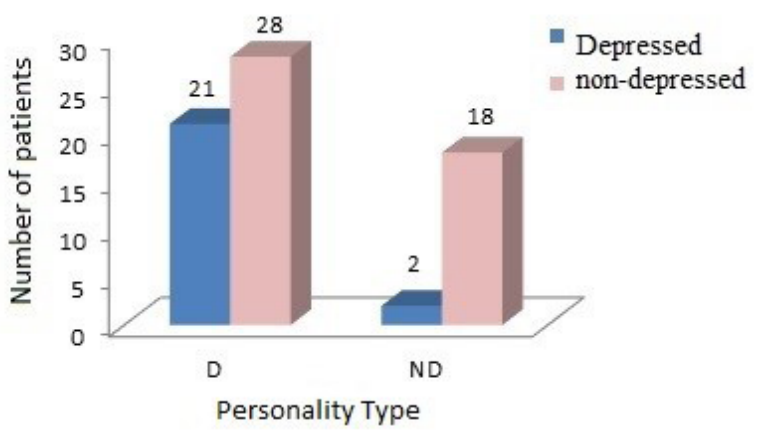

Figure 1. Comparison of the Frequency of Depression in Two Study Groups ( $p=0.01$; Fisher exact test).

Table 2. Comparison of Depression Score and Dimensions of Quality of Life After CABG in Two Study Groups

\begin{tabular}{|c|c|c|c|}
\hline \multirow{2}{*}{ Variables } & \multicolumn{2}{|c|}{ Groups } & \multirow{2}{*}{$P$ Value } \\
\hline & $\begin{array}{l}\text { Type D Personality } \\
\text { Group }(n=49)\end{array}$ & $\begin{array}{l}\text { Non-type D Personality } \\
\text { Group }(\mathbf{n}=\mathbf{2 0})\end{array}$ & \\
\hline $\begin{array}{l}\text { Depression score, } \\
\text { Median (IQR) }\end{array}$ & $8(10.50-4.50)$ & $3.50(7-1)$ & $<0.001^{\mathrm{a}}$ \\
\hline \multicolumn{4}{|c|}{ Dimensions of quality of life (Mean \pm SD) } \\
\hline Physical & $10.857 \pm 3.415$ & $14.200 \pm 2.706$ & $<0.001^{\mathrm{b}}$ \\
\hline Psychological & $13.204 \pm 2.605$ & $16.505 \pm 2.259$ & $<0.001^{\mathrm{b}}$ \\
\hline Social & $14.00 \pm 3.329$ & $15.850 \pm 3.281$ & $0.039^{b}$ \\
\hline Environmental & $12.979 \pm 2.203$ & $15.550 \pm 2.416$ & $<0.001^{\mathrm{b}}$ \\
\hline
\end{tabular}

a Student 's $t$ test; ' Mann-Whitney $U$ test.

participants' psychological, social, and environmental domains were higher than mean, while their scores in the physical domain were lower than mean. Comparing the quality of life among participants with type D personality regarding the gender showed that quality of life was equal between genders concerning all domains (Table 3 ).

The results of this study on the effect of life quality dimensions on depression status in the type $\mathrm{D}$ personality group showed that the mean scores of life quality were different in terms of psychological and social dimensions. In terms of physical and environmental dimensions, there were no significant differences (Table 4).

In addition, the quality of life in the type D-personality group after CABG surgery was compared concerning the occupational status, and there was no significant difference between employed and unemployed participants regarding any of the physical, psychological, social, and environmental domains (Table 5).

\section{Discussion}

This study compared depression and quality of life after CABG surgery in patients with and without type D personalities. The frequency of depression in this study was obtained at $33 \%$. In a study performed by Fraguas et al, it was demonstrated that $21 \%$ of patients experience depression after surgery that it was with more irritability rather than non-depressed patients. Before cardiac surgery, rate of depression was $22 \% .^{32} 88 \%$ of participants in the 
Table 3. Comparison of the Quality of Life Dimensions in type D Personality Group in Terms of the Gender ( $n=13 /$ female, $n=36 /$ male)

\begin{tabular}{lccc}
\hline \multirow{2}{*}{ Quality of Life } & \multicolumn{2}{c}{ Gender } & \multirow{2}{*}{ P Value $^{\mathrm{a}}$} \\
\cline { 2 - 3 } & \multicolumn{1}{c}{ Female } & Male & \\
\hline Physical dimension & $9.923 \pm 2.691$ & $11.194 \pm 3.615$ & 0.254 \\
Psychological dimension & $13.00 \pm 2.309$ & $13.277 \pm 2.731$ & 0.746 \\
\hline Social dimension & $13.923 \pm 3.426$ & $14.027 \pm 3.342$ & 0.924 \\
Environmental dimension & $12.692 \pm 2.393$ & $13.083 \pm 2.156$ & 0.589 \\
\hline
\end{tabular}

Data presented as Mean \pm SD.

a Student's $t$ test.

Table 4. Comparison of the Dimensions of Quality of Life in type D Personality Group According to Their Depression Status

\begin{tabular}{lccc}
\hline $\begin{array}{l}\text { Quality of Life } \\
\text { Dimensions }\end{array}$ & $\begin{array}{c}\text { With Depression } \\
(\mathbf{n = 2 1})\end{array}$ & $\begin{array}{c}\text { Without Depression } \\
(\mathbf{n = 2 8})\end{array}$ & $\boldsymbol{P}^{\text {Value }}{ }^{\mathrm{a}}$ \\
\hline Physical & $9.952 \pm 2.906$ & $11.535 \pm 3.656$ & 0.109 \\
Psychological & $11.952 \pm 2.178$ & $14.142 \pm 2.534$ & 0.003 \\
Social & $12.190 \pm 2.619$ & $15.357 \pm 3.188$ & 0.001 \\
Environmental & $12.285 \pm 2.052$ & $13.500 \pm 2.202$ & 0.055 \\
\hline
\end{tabular}

Data presented as Mean $\pm \mathrm{SD}$.

a Student's $t$ test

Table 5. Comparison of the dimensions of quality of life in type D personality group in terms of the occupational status

\begin{tabular}{lccc}
\hline Quality of life dimensions & $\begin{array}{c}\text { Employed } \\
(\mathbf{n = 2 5})\end{array}$ & $\begin{array}{c}\text { Non-employed } \\
(\mathbf{n = 2 4 )}\end{array}$ & $\boldsymbol{P ~ V a l u e ~}^{\mathrm{a}}$ \\
\hline Physical & $11.160 \pm 3.531$ & $10.541 \pm 3.335$ & 0.532 \\
\hline Psychological & $13.280 \pm 2.761$ & $13.125 \pm 2.490$ & 0.838 \\
Social & $14.200 \pm 3.391$ & $13.791 \pm 3.322$ & 0.672 \\
Environmental & $12.840 \pm 2.134$ & $13.125 \pm 2.309$ & 0656 \\
\hline
\end{tabular}

Data presented as Mean \pm SD.

a Student's $t$ test.

present study had no previous history of depression. Therefore, the increase of postoperative depression in them indicates that $\mathrm{CABG}$ surgery, as a stressor, plays a critical role in causing depression. The current method of CABG surgery (median sternotomy) affects the appearance of patients and may lead to feelings of worry and anxiety. If we can use novel surgery methods, such as minimally invasive techniques, surgery complications will decrease, and patients will return to normal life sooner.

According to our findings, the quality of life scores in the type D personality group was significantly lower than the non-type $\mathrm{D}$ group in physical, psychological, and environmental domains. Still, it is not true about the social domain. The study performed by Al-Ruzzeh and colleagues demonstrated that type $\mathrm{D}$ personality predicts the poor physical component of quality of life after cardiac surgery. ${ }^{35}$ But some other researches revealed that the quality of life had been optimum 6-12 months after surgery, including physical domain. ${ }^{36}$ Our study was performed in a period in which patients were recovering from the surgery at home. They would possibly become more satisfied with their physical status when they return to their previous social activities. Follow-up of patients for a more extended period would clarify this issue.

Based on the findings of our study, $71.01 \%$ of participants had type $\mathrm{D}$ personality, which was by the results of Pedersen and others. Their study demonstrated that type D personality is a significant risk factor for developing cardiac diseases and their poor prognosis in these patients. ${ }^{37}$ As mentioned earlier, these people had no control over their anger and are likely to express negative emotions. Due to the high percentage of this type of personality among cardiac patients, we can identify them with the help of psychiatrists and psychologists (by evaluating people using filling out questionnaires in high schools, universities, or their place of work). In addition, we can prevent adverse physical outcomes in patients with this type of personality by educating them to control their behavior to avoid unfavorable events (e.g., myocardial infarction and the following heart surgery) in the first place.

In the present study, there was no significant relationship between physical, psychological, social, and environmental quality of life and depression in type D personality group and gender. A study has reported that type D personality and cardiovascular disease were more common in males, and depression was more frequent in females. ${ }^{38}$ Our study population was mainly men; thus, this difference may be due to fewer women in our study no similar studies were found regarding this issue.

In a prospective clinical study on 65 patients via Beck's depression inventory scale, it was shown that depression and anxiety after cardiac surgery were higher than before it. ${ }^{39}$ Incidence of depression declines in older patients with type $\mathrm{D}$ personality after cardiac surgery. This may be due to the lack of awareness regarding surgery risks and their prognosis. On the other hand, older patients may have less worry and stress about the loss of function and decreased performance after surgery than younger patients. This may be the reason for the lower frequency of depression in older patients. Another reason for this may be that life expectations decrease as people age; moreover, improved physical status after heart surgery and increased life expectancy may improve their quality of life, especially in the psychological and physical domain. ${ }^{40}$

The negative effect of type D personality on quality of life after CABG surgery has been documented. It is apart

\section{Research Highlights}

\section{What Is Already Known?}

There is evidence for the impact of quality of life, psychological problems, mood disorders, anxiety disorders, sexual disorders, and sleep disorders on patients with cardiac issues and surgery with the type of personality.

\section{What Does This Study Add?}

Type D personality is associated with an increased risk of depression and poor quality of life in patients undergoing CABG. 
from depression which may be associated with type D personality. ${ }^{36}$ To improve the quality of life after CABG surgery, an expanded rehabilitation, including social and psychological support, is recommended in patients at high risk for postoperative depression (including patients with type $\mathrm{D}$ personality). ${ }^{36}$

There was no significant relationship between depression and the occupational status of participants in our study. Additionally, the relation between different domains of quality of life and occupational status was not significant. In our study, approximately half of the patients with type D personality (23 out of 49) were unemployed. So, they were not worried about losing their job or face a reduction in their occupational activities; therefore, this may reduce their depression after surgery. Maybe these patients did not pay much attention to their quality of life before surgery, and thus their condition had not changed markedly after surgery.

Type D personality is an independent factor for the prediction of adverse outcomes in patients with cardiac diseases. It may be worse in patients with type D personality who are involved by depression. ${ }^{36}$ Spindler et al study findings ${ }^{21}$ were consistent with our findings. Thus, we can reduce depression after CABG surgery by screening cardiovascular patients for type D personality.

Most of the participants in our study had a low level of education. Approximately half of them were unemployed concerning the social quality of life; therefore, heart surgery may not have been a stressor to reduce their social quality of life.

One of the limitations of the current study was that many of the participants could not fill out the questionnaires independently because they were illiterate or had unfavorable physical conditions. The researcher had to read out the questions for them. In such cases, patients may not give proper information in response to questions. In addition, using questionnaires and self-report systems may prevent the acquisition of correct and accurate data in the case of other participants.

\section{Conclusion}

Depression and quality of life are higher in patients with type $\mathrm{D}$ personality after $\mathrm{CABG}$ than patients without type $\mathrm{D}$ personality. Screening these patients can prevent future physical and psychological problems. Also, it will be helpful to use scientific and physiological methods to educate these patients regarding behavioral traits and increase their level of awareness concerning the course of the disease and its complications to improve their quality of life and prevent depression in them.

\section{Authors' Contributions}

Concept and design: SM, NKM and SH. Acquisition, analysis, or interpretation of data: NKM and SH. Drafting of the manuscript: $\mathrm{SH}, \mathrm{EH}, \mathrm{AF}$ and $\mathrm{RB}$. Critical revision of the manuscript for important intellectual content: RB. SM and SH had full access to all of the data in the study and takes responsibility for the integrity of the data and the accuracy of the data analysis.

\section{Conflict of Interest Disclosures}

The authors declare no conflicts of interest concerning the present study.

\section{Ethical Approval}

The ethics committee of Ahvaz Jundishapour University of Medical Sciences, Ahvaz, Iran, approved the study proposal (Code: IR.AJUMS.1392.REC.924). After the full explanation about the purpose and method of the study, a written informed consent was signed by all participants. Participants were also assured that all their information would be kept confidential and only be used for research purposes.

\section{Acknowledgments}

This manuscript was extracted from the M.D. dissertation of one of the authors, which been approved by the research committee by Ahvaz Jundishapur University of Medical Sciences, Ahvaz, Iran.

\section{References}

1. Roth GA, Forouzanfar MH, Moran AE, et al. Demographic and epidemiologic drivers of global cardiovascular mortality. $N$ Engl J Med. 2015;372(14):1333-1341. doi:10.1056/ NEJMoa1406656

2. Likosky DS, Dacey LJ, Baribeau YR, et al. Long-term survival of the very elderly undergoing coronary artery bypass grafting. Ann Thorac Surg. 2008;85(4):1233-1237. doi:10.1016/j.athoracsur.2007.12.066

3. Cohen DJ, Van Hout B, Serruys PW, et al. Quality of life after PCI with drug-eluting stents or coronary-artery bypass surgery. N Engl J Med. 2011;364(11):1016-1026. doi:10.1056/ NEJMoa1001508

4. Karimi M, Brazier J. Health, health-related quality of life, and quality of life: what is the difference? Pharmacoeconomics. 2016;34(7):645-649. doi:10.1007/s40273-016-0389-9

5. Rollman BL, Belnap BH, LeMenager MS, Mazumdar S, Schulberg HC, Reynolds CF 3rd. The bypassing the blues treatment protocol: stepped collaborative care for treating post-CABG depression. Psychosom Med. 2009;71(2):217230. doi:10.1097/PSY.0b013e3181970c1c

6. Ravven S, Bader C, Azar A, Rudolph JL. Depressive symptoms after CABG surgery: a meta-analysis. Harv Rev Psychiatry. 2013;21(2):59-69. doi:10.1097/HRP.0b013e31828a3612

7. Blumenthal JA, Lett HS, Babyak MA, et al. Depression as a risk factor for mortality after coronary artery bypass surgery. Lancet. 2003;362(9384):604-609. doi:10.1016/ s0140-6736(03)14190-6

8. Tully PJ, Baker RA. Depression, anxiety, and cardiac morbidity outcomes after coronary artery bypass surgery: a contemporary and practical review. J Geriatr Cardiol. 2012;9(2):197-208. doi:10.3724/sp.j.1263.2011.12221

9. Barger SD, Sydeman SJ. Does generalized anxiety disorder predict coronary heart disease risk factors independently of major depressive disorder? J Affect Disord. 2005;88(1):87-91. doi:10.1016/j.jad.2005.05.012 
10. Kuhl EA, Fauerbach JA, Bush DE, Ziegelstein RC. Relation of anxiety and adherence to risk-reducing recommendations following myocardial infarction. Am J Cardiol. 2009;103(12):1629-1634. doi:10.1016/j.amjcard.2009.02.014

11. Tully PJ, Baker RA, Knight JL, Turnbull DA, Winefield HR. Neuropsychological function 5 years after cardiac surgery and the effect of psychological distress. Arch Clin Neuropsychol. 2009;24(8):741-751. doi:10.1093/arclin/ acp082

12. Frasure-Smith $\mathrm{N}$, Lespérance $\mathrm{F}$, Irwin $\mathrm{MR}$, Sauvé $\mathrm{C}$, Lespérance J, Théroux P. Depression, C-reactive protein and two-year major adverse cardiac events in men after acute coronary syndromes. Biol Psychiatry. 2007;62(4):302-308. doi:10.1016/j.biopsych.2006.09.029

13. McCaffery JM, Frasure-Smith N, Dubé MP, et al. Common genetic vulnerability to depressive symptoms and coronary artery disease: a review and development of candidate genes related to inflammation and serotonin. Psychosom Med. 2006;68(2):187-200. doi:10.1097/01.psy.0000208630.79271. $\mathrm{a} 0$

14. Jokela $M$, Pulkki-Råback $L$, Elovainio $M$, Kivimäki $M$. Personality traits as risk factors for stroke and coronary heart disease mortality: pooled analysis of three cohort studies. $J$ Behav Med. 2014;37(5):881-889. doi:10.1007/s10865-0139548-Z

15. Mols F, Denollet J. Type D personality in the general population: a systematic review of health status, mechanisms of disease, and work-related problems. Health Qual Life Outcomes. 2010;8:9. doi:10.1186/1477-7525-8-9

16. Denollet J, Conraads VM. Type D personality and vulnerability to adverse outcomes in heart disease. Cleve Clin J Med. 2011;78 Suppl 1:S13-19. doi:10.3949/ccjm.78. s 1.02

17. Middel B, El Baz N, Pedersen SS, van Dijk JP, Wynia K, Reijneveld SA. Decline in health-related quality of life 6 months after coronary artery bypass graft surgery: the influence of anxiety, depression, and personality traits. J Cardiovasc Nurs. 2014;29(6):544-554. doi:10.1097/ JCN.0b013e3182a102ae

18. Denollet J. Personality and coronary heart disease: the type-D scale-16 (DS16). Ann Behav Med. 1998;20(3):209215. doi: $10.1007 / \mathrm{bf} 02884962$

19. Denollet J. DS14: standard assessment of negative affectivity, social inhibition, and type D personality. Psychosom Med. 2005;67(1):89-97. doi:10.1097/01.psy.0000149256.81953.49

20. Svansdottir E, van den Broek KC, Karlsson HD, Gudnason T, Denollet J. Type D personality is associated with impaired psychological status and unhealthy lifestyle in Icelandic cardiac patients: a cross-sectional study. BMC Public Health. 2012;12:42. doi:10.1186/1471-2458-12-42

21. Spindler H, Kruse C, Zwisler AD, Pedersen SS. Increased anxiety and depression in Danish cardiac patients with a type D personality: cross-validation of the type D Scale (DS14). Int J Behav Med. 2009;16(2):98-107. doi:10.1007/ s12529-009-9037-5

22. Hausteiner C, Klupsch D, Emeny R, Baumert J, Ladwig $\mathrm{KH}$. Clustering of negative affectivity and social inhibition in the community: prevalence of type D personality as a cardiovascular risk marker. Psychosom Med. 2010;72(2):163171. doi:10.1097/PSY.0b013e3181cb8bae

23. Denollet J, Sys SU, Brutsaert DL. Personality and mortality after myocardial infarction. Psychosom Med. 1995;57(6):582591. doi:10.1097/00006842-199511000-00011

24. Pedersen SS, Denollet J. Type D personality, cardiac events, and impaired quality of life: a review. Eur J Cardiovasc Prev Rehabil. 2003;10(4):241-248. doi:10.1097/00149831200308000-00005

25. Emons WH, Meijer RR, Denollet J. Negative affectivity and social inhibition in cardiovascular disease: evaluating type-D personality and its assessment using item response theory. J Psychosom Res. 2007;63(1):27-39. doi:10.1016/j. jpsychores.2007.03.010

26. Skevington SM, Lotfy M, O'Connell KA. The World Health Organization's WHOQOL-BREF quality of life assessment: psychometric properties and results of the international field trial. A report from the WHOQOL group. Qual Life Res. 2004;13(2):299-310. doi:10.1023/ b:qure.0000018486.91360.00

27. Nejat S, Montazeri A, Holakouie Naieni K, Mohammad K, Majdzadeh SR. The World Health Organization quality of life (WHOQOL-BREF) questionnaire: translation and validation study of the Iranian version. Journal of School of Public Health and Institute of Public Health Research. 2006;4(4):1-12. [Persian].

28. Beck AT, Ward CH, Mendelson M, Mock J, Erbaugh J. An inventory for measuring depression. Arch Gen Psychiatry. 1961;4:561-571. doi:10.1001/ archpsyc.1961.01710120031004

29. Beck AT, Steer RA, Carbin MG. Psychometric properties of the Beck Depression Inventory: twenty-five years of evaluation. Clin Psychol Rev. 1988;8(1):77-100. doi:10.1016/0272-7358(88)90050-5

30. Davies B, Burrows G, Poynton C. A comparative study of four depression rating scales. Aust N Z J Psychiatry. 1975;9(1):21-24. doi:10.3109/00048677509159816

31. Ghassemzadeh H, Mojtabai R, Karamghadiri N, Ebrahimkhani N. Psychometric properties of a Persianlanguage version of the Beck Depression Inventory--second edition: BDI-II-PERSIAN. Depress Anxiety. 2005;21(4):185192. doi:10.1002/da.20070

32. Júnior RF, Ramadan ZB, Pereira AN, Wajngarten M. Depression with irritability in patients undergoing coronary artery bypass graft surgery: the cardiologist's role. Gen Hosp Psychiatry. 2000;22(5):365-74.

33. Tashakkori A, Barefoot J, Mehryar AH. What does the Beck Depression Inventory measure in college students? evidence from a non-western culture. J Clin Psychol. 1989;45(4):595602. doi:10.1002/1097-4679(198907)45:4<595::aidjclp2270450415>3.0.co;2-4

34. Hojat M, Shapurian R, Mehryar AH. Dimensionality of the short form of the Beck Depression Inventory: a study with Iranian college students. Psychol Rep. 1986;59(3):1069-1070. doi:10.2466/pr0.1986.59.3.1069

35. Al-Ruzzeh S, Athanasiou T, Mangoush O, et al. Predictors 
of poor mid-term health related quality of life after primary isolated coronary artery bypass grafting surgery. Heart. 2005;91(12):1557-1562. doi:10.1136/hrt.2004.047068

36. Fatima K, Yousuf-ul-Islam M, Ansari M, Bawany FI, Khan MS, Khetpal A, et al. Comparison of the Postprocedural Quality of Life between Coronary Artery Bypass Graft Surgery and Percutaneous Coronary Intervention: A Systematic Review. Cardiol Res Pract. 2016;2016:7842514. doi:10.1155/2016/7842514

37. Pedersen SS, Denollet J. Is type D personality here to stay? emerging evidence across cardiovascular disease patient groups. Curr Cardiol Rev. 2006;2(3):205-213. doi:10.2174/157340306778019441

38. Staniute M, Brozaitiene J, Burkauskas J, Kazukauskiene N,
Mickuviene N, Bunevicius R. Type D personality, mental distress, social support and health-related quality of life in coronary artery disease patients with heart failure: a longitudinal observational study. Health Qual Life Outcomes. 2015;13:1. doi:10.1186/s12955-014-0204-2

39. Fruitman DS, MacDougall CE, Ross DB. Cardiac surgery in octogenarians: can elderly patients benefit? quality of life after cardiac surgery. Ann Thorac Surg. 1999;68(6):21292135. doi:10.1016/s0003-4975(99)00818-8

40. Krannich JH, Weyers P, Lueger S, Herzog M, Bohrer T, Elert O. Presence of depression and anxiety before and after coronary artery bypass graft surgery and their relationship to age. BMC Psychiatry. 2007;7:47. doi:10.1186/1471$244 \mathrm{x}-7-47$ 